\title{
EL NUEVO TERRENO DE LA LUCHA DE CLASES Y LOS PROBLEMAS DE LA REVOLUCIÓN EN AMÉRICA LATINA*
}

$\mathrm{E}$ n nuestras dos reuniones anteriores he tratado de presentar, en sus líneas generales, las tendencias y las características nuevas con que se mueve y se configura el terreno actual de la lucha de clases en América Latina. Ahora, después de esto, supongo que todos nosotros tendríamos necesidad de contestar a una pregunta obligada: ¿Y frente a todo esto, qué vamos a hacer? Yo supongo también, o mejor, estoy seguro, que ustedes son totalmente sensatos y no están esperando que acuñe aquí respuestas a esta gran pregunta. En verdad, creo que en esta ocasión y en un lugar como éste, es más pertinente intentar formular los problemas, por lo menos algunos de los más importantes, a los cuales

* Publicado en Quijano, Aníbal 1974 Crisis imperialista y clase obrera en América Latina (Lima: Edición del autor) pp. 87-116. nos enfrentamos en este nuevo escenario de las luchas de clase.

\section{LA MESA DE TRES PATAS}

Para partir, quisiera sugerir que en relación a los problemas de la revolución socialista, dentro y fuera, de América Latina, necesitamos todavía estrechar y sistematizar la articulación entre tres elementos básicos; construir lo que, con una imagen menor, podríamos llamar algo así como una mesa de tres patas: una teoría que efectivamente dé cuenta de la realidad y de sus movimientos, la organización y movilización política de las clases dominadas, y el desarrollo de la capacidad de violencia revolucionaria de las masas.

Me parece que en América Latina, como lo muestra bien la experiencia actual, no 
hemos podido aún conseguir plenamente la sistemática articulación de esos tres elementos. Hemos tenido movimientos populares fuertemente organizados, pero en los cuales los retrasos y las limitaciones teóricas han producido conducciones vacilantes; u organizaciones con notable capacidad de violencia revolucionaria, pero cuya conexión con el movimiento organizado de las masas ha sido en todos los casos precaria. O, finalmente, núcleos políticos con una relativamente notable lucidez teórica, pero cuya audiencia en las masas, cuya presencia real en el seno de ellas y cuya capacidad de trabajo organizado han sido, casi siempre, débiles. Y hasta tanto que no hayamos podido construir esta mesa de tres patas, serán siempre más probables las derrotas que los triunfos de las luchas revolucionarias.

\section{LOS PROBLEMAS DE LA TEORÍA}

En la reunión pasada, aludí a tres problemas cuya investigación y discusión me parecen decisivas para la construcción de una estrategia revolucionaria en América Latina, y que resultan del esquema crítico-explicativo presentado previamente.
En primer lugar, lo que hemos denominado como el agotamiento de las bases objetivas del nacionalismo antioligárquico, como parte de una estrategia revolucionaria conducente al socialismo, y cuyo agotamiento explica el auge y la declinación actual del nacionalismo de origen pequeñoburgués.

Sobre este problema, creo que la confusión es todavía muy extendida, porque las condiciones propias de la dominación imperialista en el pasado ciclo del capital permitieron que dentro de la teoría revolucionaria se concluyera, correctamente para ese período, que en toda sociedad nacional sometida a la dominación imperialista, la burguesía dependiente era o podía ser nacionalista. En consecuencia era no solamente posible sino también necesario, que se trabajara en la construcción de una alianza de los trabajadores con la burguesía nacional, para un enfrentamiento conjunto contra la burguesía imperialista.

Y en efecto, si no en todas partes, existían algunas bases objetivas para que aquello pudiera ser así en América Latina. Las dos principales, pueden ser formuladas brevemente:

1) En la mayoría de países sometidos a la dominación imperialista, el modelo central de acumulación era de carácter semicolonial, una 
de cuyas bases fundamentales era la extendida persistencia de relaciones de producción de origen precapitalista, estructuralmente articuladas a las necesidades de acumulación de un capital monopolista con sedes casi exclusivamente externas de realización y de acumulación. En esa situación, las posibilidades y necesidades de expansión del mercado interno, de formación o de ampliación de un circuito interno de acumulación, estaban relativamente bloqueadas y, en consecuencia, las posibilidades y necesidades de expansión del poder económico propio de las burguesías dependientes. En las regiones y países colonizados, esa situación estaba agravada por el bloqueo de la participación de las burguesías nativas en el poder político.

En otros términos, en las contradicciones de la estructura de las relaciones de producción se asentaba una base objetiva de conflictos entre la burguesía imperialista y la dependiente.

En América Latina, a pesar de que en términos generales esa era la situación en todos los países, la posibilidad de conflictos reales entre la burguesía imperialista y la dependiente no se dio con la misma profundidad en todos ellos.

En algunos países, por determinaciones históricas bien precisables, pudieron emerger núcleos importantes de burguesía dependiente en el control directo de recursos igualmente importantes de producción. Debido a eso, dentro de su asociación subordinada con la burguesía monopolista o imperialista, aquellos núcleos de burguesía dependiente tenían interés y capacidad para intentar enfrentamientos parciales con la burguesía imperialista, admitiendo inclusive apoyarse en movimientos populares para tratar de hacer reformas que permitieran, al mismo tiempo, la expansión de las bases de un circuito interno de acumulación y de realización, y la mayor participación en los beneficios de la producción capitalista como tal.

En otros países, en cambio, las bases del desarrollo capitalista eran tan extremamente incipientes y, por lo tanto, los respectivos núcleos de burguesía capitalista, que al producirse la penetración directa de capital imperialista en ellos la burguesía imperialista se articuló políticamente con una oligarquía de terratenientes señoriales y comerciantes. O, en otros casos, los núcleos emergentes de burguesía nacional sin ser despreciables estaban políticamente debilitados y la burguesía imperialista pudo apoderarse de la práctica totalidad de los recursos de producción en ese momento significativa, reduciendo a la burguesía dependiente a una condición económica y políticamente demasiado débil. 
En estos últimos países, o no existía una burguesía dependiente en tanto que una clase social efectiva, sino como núcleos reducidos y dispersos, o fue reducida a una condición de debilidad tan extrema que no tuvo en momento alguno capacidad para un enfrentamiento importante con la burguesía imperialista, y, por lo mismo, tampoco un interés real para hacerlo, ya que a ese nivel de incapacidad se produce también una falta de interés efectivo. Sobre todo, porque en esas condiciones, los movimientos populares antioligárquicos, obligaron a este tipo de burguesías dependientes a apoyarse y entregarse aún más profundamente a la dominación imperialista.

Todos sabemos que a pesar de estas diferencias profundas entre los países latinoamericanos, la mayor parte de los movimientos políticos que se reclaman socialistas, intentaron la aplicación mecánica e indiscriminada de una estrategia de alianzas con las burguesías nacionales, en todas partes. Y en ciertos países, casi siempre a destiempo.

Actualmente, el proceso de cambios que hemos venido examinando ha modificado aquella situación de manera fundamental. En la medida en que se van ampliando y reorganizando las bases del capitalismo, las fuentes de conflicto entre la burguesía dependiente y la imperialista se han ido reduciendo, cediendo el lugar a una cada vez más profunda identificación de sus intereses concretos.

2) Una segunda base de conflictos entre ambos estratos de la burguesía era la notable limitación de los márgenes de autonomía, que los Estados imperialistas permitían o toleraban a los Estados nacional-dependientes, de un lado, porque el bloqueo a los intereses propios de las burguesías dependientes en la arena económica estaba reforzado por el bloqueo a la autonomía de su participación en el poder político; y de otro lado, porque la competencia entre las burguesías nacional-imperialistas, obligaba a sus respectivos Estados a someter a los Estados nacional-dependientes a un control muy riguroso.

Esa situación correspondía al hecho de que en ese período, el capital monopolista estaba dividido entre las manos de burguesías nacional-imperialistas que se disputaban los mercados, los recursos productivos, y el control político de zonas y países para garantizar el control de sus recursos económicos.

En esas condiciones, una burguesía dependiente que quedaba colocada bajo el dominio de una de las burguesías nacional-imperialistas, no tenía posibilidades de diversificar sus 
relaciones económicas con las de otros países y de ampliar sus márgenes de beneficios. La autonomía relativa de la burguesía dependiente en el plano político era, por lo tanto, un interés de aquella y una fuente de conflictos con la burguesía imperialista.

La competencia entre las burguesías de los diversos países imperialistas no se ha terminado. Es ya claro, sin embargo, que actualmente esa competencia se ha modificado en varios sentidos, admitiendo una creciente capacidad de las burguesías dependientes para multilateralizar sus relaciones económicas y políticas y, en ese sentido, disponer de un margen relativamente ampliado de autonomía respecto del control de un determinado Estado imperialista en particular, sin que eso, signifique su salida del orden imperialista en su conjunto.

El proceso de creciente internacionalización del capital, el surgimiento de las grandes corporaciones conglomeradas transnacionales, implica una autonomía relativa importante de la política de estas respecto de los Estados imperialistas, y amplían también las posibilidades de maniobra de las burguesías dependientes dentro del campo imperialista al que pertenecen.

Y, no menos importante, el hecho de que a partir de la Segunda Guerra Mundial todas estas modificaciones en la estructura del imperialismo, se llevaron a cabo bajo la total hegemonía del Estado norteamericano, el cual fue emergiendo de ese modo ya no solamente como un Estado nacional imperialista en competencia con otros, sino cada vez más como el Estado imperialista hegemónico, que habiendo reducido muy drásticamente la capacidad político-militar de los otros Estados imperialistas, asumía ya no solamente la defensa de sus intereses nacional-imperialistas, sino la defensa de los intereses del conjunto del sistema imperialista.

Dentro de este nuevo contexto, la competencia entre las burguesías imperialistas, sin que sus bases nacionales se hayan terminado, va asumiendo la forma de una competencia inter-empresas multinacionales, combinada con la competencia inter-nacional. Pero, además, las burguesías nacional-imperialistas que todavía pudieran operar como tales, no tienen hoy día las posibilidades político-militares que les permitían, a cada una por separado, buscar el control aparte de una zona o de un país en contra de las demás. Ninguna de ellas puede ir demasiado lejos en esa dirección, en el momento en que sus conflictos internos están ya subordinados definitivamente a las necesidades de la defensa global del sistema. 
De su lado, el propio Estado imperialista hegemónico no podría ya operar solamente como representante de los intereses de una burguesía nacional-imperialista particular. El capital monopólico de origen norteamericano tiene el dominio del sistema en tanto que opera en su carácter de capital monopólico internacional, dominador y expresión del sistema en su conjunto. El Estado norteamericano, en tanto que Estado imperialista hegemónico, requiere ahora simultáneamente defender sus intereses nacionales, y arbitrar entre éstos y las necesidades de defensa global del sistema.

Se ha cerrado así, o está terminando de cerrarse, en América Latina, el ciclo histórico en el cual, existían bases estructurales de contradicciones importantes entre los intereses de la burguesía imperialista y aquellos de la burguesía dependiente.

Asistimos hoy día, en América Latina, a una cada vez más profunda asociación de intereses entre burguesía imperialista y burguesía dependiente, al mismo tiempo en que los Estados nacional-dependientes disponen visiblemente de un margen de maniobra suficientemente amplio como para multilateralizar las relaciones económicas y políticas de sus países (de los capitales que allí operan), de un modo bastante diferente que en el período anterior.
Todo ello supone, a mi juicio, la necesidad de replantear a fondo el razonamiento político que colocaba y todavía coloca el nacionalismoantioligárquico, como una etapa y una parte real de una estrategia de lucha por el socialismo. Es decir, las bases teóricas del reformismo en América Latina, cobijadas en el seno mismo de movimientos que sostienen explícitamente su orientación socialista, son despojadas ahora de todo sustento en la realidad.

En segundo lugar, y en estrecha relación con el problema anterior, me parece necesario insistir en que esa nueva situación de los Estados nacional-dependientes es parte integrante de la alteración de sus funciones concretas respecto del problema de la acumulación de capital.

Por las razones que acabamos de anotar, en el ciclo que ahora termina la estatización de recursos de producción dentro de nuestros países, fue durante un momento un curso objetivo de nacionalización del capital, en la medida en que eso correspondía al carácter objetivo de las contradicciones importantes de intereses entre la burguesía imperialista y la dependiente, contradicciones que no por ser parciales eran menos reales, por lo menos en algunos países.

Sin embargo, es evidente hoy día que la estatización de capital ya no es en América Latina, sinónimo de nacionalización automáticamente. 
El desarrollo de las tendencias hacia el capitalismo de Estado, se procesa actualmente como parte de una asociación del capital estatal y del capital monopólico internacional e interno, en todos nuestros países. Y esta asociación está pasando a ser el eje nuevo de la expansión del dominio del capital monopolista internacional en la economía latinoamericana.

He insistido, en la reunión anterior, que el capitalismo de Estado en la actualidad es el resultado, simultáneamente, de las necesidades del propio grado de desarrollo de las fuerzas productivas dentro del capitalismo en estos países, y de las necesidades de expansión de las bases de la acumulación internacional del capital monopólico, así como de los problemas derivados de la necesidad de control político de los conflictos de clase en el momento mismo de este reajuste de las bases del capitalismo y de la hegemonía de la burguesía monopolista en el Estado.

Eso significa que la asociación entre capital estatal y capital monopólico internacional e interno, que funda el desarrollo de las tendencias hacia el capitalismo de Estado, no solamente no está exenta de contradicciones, sino que tampoco agota plenamente las contradicciones originadas en la situación anterior. Sin embargo, el hecho es que éstas últimas están fundamentalmente subordinadas a las que se derivan de la nueva estructura. Es decir, lo que pueda quedar de los intereses nacionales del capital y de la burguesía dependientes, se subsumen en las necesidades de la asociación con el capital y la burguesía monopolista internacional y sus contradicciones.

Como hemos visto antes, esas nuevas contradicciones son aquellas que se derivan de las necesidades de consolidación de los circuitos internos de acumulación en unos países, o de las necesidades de ampliar la inserción en el circuito internacional de reproducción ampliada en otros, frente a los intereses inmediatos del capital monopolista internacional. $\mathrm{Y}$ de otro lado, las que se derivan de las necesidades del Estado de operar ahora como empresario capitalista, frente a sus necesidades agravadas de arbitrar y controlar los conflictos sustantivos entre las clases, en el preciso período de la depuración y de la profundización de esos conflictos.

No creo necesario detenernos en estos problemas ahora, puesto que fueron examinados ya en la pasada reunión. Quizás, no obstante, no es inútil enfatizar que esas contradicciones tenderán necesariamente a profundizarse, en el curso de agudización de los conflictos político-sociales, en torno de los propios problemas 
del capitalismo de Estado y de las nuevas formas de dominación política que éste implica en la actualidad.

Los soportes, contradicciones y límites del capitalismo de Estado, como posibilidad de desarrollo de un nacionalismo antiimperialista y de democratización de la sociedad y del Estado, parten de una posible fase de revolución democrático-burguesa nacionalista, muestran claramente que una concepción de la revolución fundada en esta alternativa sólo puede servir para mantener la confusión en la conciencia política de los trabajadores.

Finalmente, por todas esas razones, es pertinente sostener que la continuidad de formulaciones políticas que conciben el proceso revolucionario orientado al socialismo, como dividido en dos etapas, una democrático-nacionalista primero, y otra socialista después, no tiene más asideros históricos objetivos.

Como hemos visto una y otra vez, el proceso de expansión y de reorganización de las bases del capitalismo en América Latina, de depuración de la estructura de clases y de las bases sociales concretas y de las funciones del Estado, no han cancelado ni pueden cancelar, bajo el reino del capital monopólico, el conjunto de problemas y de tareas emanadas de la persistencia de relaciones de producción de origen precapitalista, de formas oligárquicas de dominación política y social.

El problema que de allí se desprende no es, sin embargo, que sea necesario primero liquidar todo aquello, como condición para la lucha contra el dominio del capital. Antes como ahora, pero sobre todo ahora, aquello se mantiene por el dominio del capital, en primer término, porque éste es en América Latina ante todo el dominio del capital monopolista internacional.

En consecuencia, la tarea central de la revolución en América Latina es la destrucción del dominio del capital monopólico internacional y de sus bases políticas y sociales, como condición para la erradicación de todas las formas de dominación que aquel mantiene. Esta es, por eso, una tarea al mismo tiempo nacional o antiimperialista y anticapitalista. Esto es, socialista.

De eso no se desprende, no obstante, que esa sea la única tarea, es decir, no todo en esta revolución por hacer comprende el socialismo. De lo que se trata aquí es de una combinación y de una superposición entre las necesidades de una revolución democrático-nacionalista y de una revolución socialista, de la liberación nacional y de la liberación de clase. Pero es la iniciación de la última que se coloca como condición de la otra, por obra de las condiciones 
específicas en que se produjo en nuestros países la dominación del capital bajo la forma de la dominación imperialista.

La fórmula que algunas tendencias revolucionarias utilizan recientemente, de una revolución por etapas pero ininterrumpida, puede ser una formulación lógica pero no me parece que recupere las necesidades reales de la historia. Ambas revoluciones se combinan, sobre la base de la iniciación de la más avanzada. La destrucción del dominio del capital monopolista internacional, no implica automáticamente la destrucción del dominio del capital en general; pero es la condición de la realización de las tareas democrático-nacionales, y a largo plazo, de la destrucción del entero dominio del capital.

Creo que es útil recordar aquí que cuando Lenin en las famosas Tesis de abril, sostenía que la revolución democrático burguesa se había agotado y era entonces indispensable enrumbarse en la vía de la revolución socialista, no estaba diciendo que las tareas propias de la revolución democrático-burguesa se habían efectivamente realizado en la Rusia de abril de 1917, cuando la reforma agraria no estaba ni siquiera iniciada. Lo que estaba obviamente diciendo es que, por esa vía la de la revolución democrático-burguesa, era ya imposible avan- zar en la revolución, y que para poder cumplir inclusive esas tareas era necesario poner en marcha las tareas iniciales propias de la revolución socialista.

En ese mismo sentido, creo que la experiencia histórica concreta de América Latina muestra, desde hace bastante tiempo, que todos los procesos revolucionarios que se limitaron a las tareas propias del nacionalismo-antioligárquico no pudieron consolidarse realmente en esa dirección. Y que solamente esas tareas pudieron ser llevadas a cabo plenamente, a través de la iniciación de las tareas propias de la destrucción del dominio del capital, como en Cuba.

Eso implica, naturalmente, la conquista del poder político por los trabajadores, como condición sine qua non. Pero esa conquista del poder político, no puede ser lograda, a su vez, sino a través de una estrategia de lucha despejada de todas las confusiones teóricas procedentes del ciclo anterior.

\section{TEORÍA DE CLASE Y CONCIENCIA DE CLASE}

Aquí, por eso, se plantea un problema de fondo: el de la relación entre la teoría de clase y la conciencia de clase. Pues si la teoría revolucio- 
naria sobre el capital que hoy se desarrolla en América Latina, no llega a ser parte integrante de la conciencia política de los trabajadores, y no solamente patrimonio de sectores intelectuales, profesionales, o de grupos igualmente restrictos de trabajadores, esa teoría no llegara a ser concretamente eficaz para las luchas revolucionarias de las masas de trabajadores.

La conciencia de clase es, por cierto, una conciencia concreta. Como dijo Fernando Claudin en una reunión pasada, "la conciencia de clase es un fenómeno histórico”. Es decir, se forma y se transforma en el curso concreto de los cambios en la estructura de relaciones de clase y de las luchas de clase. Pero la historia del capitalismo es, también, la historia de sus desigualdades y de sus combinaciones. En ese sentido, cuando hablamos de la conciencia de clase del proletariado y, por lo tanto, de la madurez política de esta clase, estamos también necesariamente hablando de varios niveles posibles de conciencia de clase, simultáneamente presentes en el mismo horizonte histórico.

Una es, por consecuencia, la conciencia y la madurez política posibles en el proletariado de los centros de desarrollo del capitalismo, y otra posible en el proletariado latinoamericano. Allá, a pesar de que es visible que una parte muy importante del proletariado no ha recupe- rado aun sus problemas en el más alto nivel político, la propia cultura y la vida cotidiana están generando una nueva subjetividad en el seno de la clase. Aquí, en cambio, no estamos todavía asistiendo en concreto a la maduración del capitalismo en ese límite, que funda la madurez de las posibilidades de una sociedad socialista en el seno mismo de su antagonista.

Por eso, cuando hablamos de la conciencia de clase del proletariado latinoamericano, estamos aludiendo a algo muy preciso: la conciencia de cuál es el escenario en que se mueve, de cuáles son las tendencias fundamentales que se mueven en este escenario, cuáles son sus enemigos concretos, sus formas específicas de acción y de poder, sus límites y sus debilidades, y por lo tanto cuáles son las propias potencialidades del proletariado y, por lo tanto sus alternativas concretas.

El hecho de que el proletariado se haya constituido, o esté ya en trance de constituirse, como clase objetivamente central dentro del conjunto de los dominados y ya no solamente como virtualidad para el futuro, en la generalidad de los países latinoamericanos; el hecho, de que sus relaciones de clase estén depurándose, profundizándose, en todas sus dimensiones; todo ello implica, también, que estamos en presencia de una nueva po- 
tencialidad política del proletariado, para convertirse en la clase políticamente hegemónica de manera concreta, en el seno de las masas dominadas para disputar el poder en la sociedad.

Sin embargo, como nos lo recuerda toda la experiencia histórica, todo eso no es suficiente para que de allí se derive una madura conciencia político-revolucionaria en la clase. El problema, a partir de aquí, es tratar de ver con qué dificultades se enfrentan los trabajadores latinoamericanos, para lograr que esta situación objetiva se convierta también en la situación subjetiva de la clase, y eso pase, a su vez, a convertirse en una condición objetiva de la realidad.

En América Latina, con la excepción de dos países, el proletariado no ha logrado aún independizarse plenamente de la influencia de las secreciones ideológicas de origen burgués y pequeñoburgués, y en particular de la herencia de la ideología del populismo nacionalista y antioligárquico. Los dos únicos países donde, a mi juicio, el proletariado ganó la emancipación de su conciencia respecto de la ideología burguesa o de sus intermediarios pequeñoburgueses son Chile y Bolivia. Eso no impide, por supuesto, reconocer en varios otros países la presencia de importantes núcleos de proletariado que se han desarrollado en la misma dirección.

Para los problemas que estamos considerando es importante hacer, aunque de paso, algunas reflexiones acerca de las condiciones que permitieron al proletariado de esos dos países, tan diferentes entre sí, la emancipación de su conciencia de clase. Debe ser claro para ustedes que, en ausencia de investigaciones específicas, sólo podemos apuntar aquí algunas hipótesis.

En el caso de Chile, me parece que el proletariado, en tanto que una parte significativa de la población trabajadora, apareció más temprano que en ningún otro país de América Latina. En esa magnitud, debido a las características de la explotación capitalista del salitre, que iniciada en territorios ajenos desde mediados del siglo pasado, terminó dentro del país chileno.

La explotación salitrera requería desde el comienzo una masa muy grande de trabajadores, tanto por las características de la dispersa ubicación de ese fertilizante en las inmensas llanuras desérticas, como por las propias características del nivel tecnológico empleado por el capital. Se formó de esa manera una masa proletarizada numerosa y relativamente segregada del contacto cotidiano con el resto de la población, sometida a una forma particularmente dura de explotación, primero bajo ca- 
pitalistas nacionales chilenos y posteriormente bajo el capital inglés.

Las luchas proletarias se iniciaron, por eso mismo, en Chile antes que en los demás países, dando paso al surgimiento de un movimiento de organización sindical y política que, inclusive, tendió desde sus inicios hacia una orientación socializante antes de la Revolución rusa de 1917. Y después de ésta, sus repercusiones políticas en América Latina encontraron ya a ese proletariado chileno en condiciones de hacer el transito efectivo a una orientación socialista definida; de todo lo cual emergieron los más importantes partidos de la clase obrera que hayan existido hasta aquí en América Latina. Nada de lo que sucedió en ese país hasta hoy día ha sido desde entonces ajeno a esta presencia organizada del proletariado, desde la ampliación y la profundización de las formas propias de la democracia burguesa, hasta la reciente disputa por el poder y la entronización de un fascismo militarista.

En Bolivia, el proceso se dio de modo muy diferente en su conjunto, pero también sobre la base de algunas importantes similitudes. Cuando se produce en gran escala la explotación de estaño, los capitales surgidos en esa explotación se integrarán a la masa global del capital monopolista internacional, a despe- cho del origen boliviano de los dueños de ese capital. La inexistencia de otros sectores de producción, en los cuales el capitalismo tuviera algún desarrollo significativo, hizo que ese capital monopolista que controlaba las minas, se aliara políticamente con los terratenientes señoriales y comerciantes, para controlar el poder del Estado. Es decir, aparte del reducido núcleo de burguesía monopolista dueña de las minas, en Bolivia no era posible encontrar existiendo como clase, hasta hace no mucho tiempo, una burguesía interna capaz de intentar y de lograr el dominio ideológico sobre el proletariado minero, enfrentado en una relación de explotación sin atenuantes de género alguno, al capital imperialista y, además, como en el caso chileno, en una situación de relativa segregación del contacto cotidiano respecto del resto de la sociedad.

Eso permitió que los reducidos núcleos de sectores sociales medios, que después de la Guerra del Chaco fueron orientándose hacia posiciones nacionalistas y antioligárquicas radicales, no pudieran tampoco lograr en la misma medida que en otros países, una influencia totalmente dominante sobre ese proletariado minero, mientras que los núcleos intelectuales de orientación definidamente socialista pudieron, en cambio, contribuir a la educación socia- 
lista de ese proletariado, precisamente sobre la base de la especial situación de clase de esos trabajadores. Desde entonces, éstos se fueron desarrollando como una de las más avanzadas fracciones del proletariado latinoamericano, a pesar de que la brutalidad represiva desatada permanentemente sobre ellos traba aún, por medio de sucesivas masacres de cuadros de vanguardia, la consolidación de organizaciones políticas acordes con el grado de desarrollo de la conciencia política de esos trabajadores.

La profundidad de los logros de la Revolución popular del 52 fue ante todo el resultado de la acción política de ese proletariado, y a pesar de su reciente derrota, esa clase junto con la de Chile, son las que han protagonizado los dos, hasta ahora únicos, procesos en América Latina de disputa abierta por el poder con una orientación explícitamente socialista, bajo el comando concreto del proletariado.

Estos dos casos ilustran, en mi opinión, un hecho significativo. El proletariado pudo emancipar su conciencia política, por la ausencia de capas burguesas y pequeñoburguesas, con la capacidad de determinar los límites del desarrollo ideológico de los trabajadores, en el caso boliviano; o, porque el proletariado se desarroló como clase, en una situación relativamente aislada al comienzo, respecto de las posibilida- des de influencia directa de la burguesía y de las capas medias, en Chile.

En cambio en todos los otros países, los núcleos centrales del proletariado estuvieron desde la partida colocados en una situación que permitía la influencia de ideologías de origen burgués o pequeñoburgués. Y en todos esos países, esa herencia pesa aún de manera importante como una de las dificultades principales para la emancipación política del proletariado.

Como consecuencia, los movimientos populares más importantes en todos estos países, se desarrollaron bajo el comando ideológico y político de sectores medios y de fracciones de la propia burguesía en conflicto con la burguesía imperialista.

Actualmente, sin embargo, el proceso de expansión del capitalismo y de depuración relativa de las relaciones de clases lleva al deterioro incesante de las bases del predominio ideológico de los sectores medios sobre el proletariado. A pesar de que en este proceso esas capas medias se han expandido y se expanden cada vez más, los intereses concretos de estas capas han ido acomodándose a la nueva configuración de la matriz productiva y social, asimilándose como intermediarios burocráticos de la explotación del capital sobre el trabajo y desembocando su orientación nacionalista 
en el sostenimiento de las actuales tendencias hacia el capitalismo de Estado, dentro de cuyo desarrollo pueden encontrar ahora un papel decisivo y una ampliación de sus oportunidades políticas.

Como consecuencia, esas capas medias de creciente carácter tecnoburocrático han venido perdiendo interés y capacidad para liderar movimientos populares en contra de las formas concretas de dominación, y buscando en cambio mantener su predominio político sobre los trabajadores para una finalidad opuesta: subordinarlos a ideologías de conciliación de clase, integrarlos políticamente a las necesidades e intereses de la asociación entre capital estatal y capital monopolista internacional, a la acción propia del capital estatal y a las formas de dominio político corporativo que aquel requiere sobre las masas.

Todo eso significa para el proletariado, y para los militantes revolucionarios, la necesidad de erradicar y destruir la influencia ideológica y política de esas capas medias, intermediadoras de los intereses de la burguesía. Y esa tarea no puede ser cumplida sin la destrucción de las bases teóricas de crítica y de interpretación de la sociedad en América Latina, que proceden del campo burgués grande o pequeño. Porque si bien se puede observar en varios países de
América Latina un continuado e irreversible debilitamiento del control político concreto de esas capas medias sobre los trabajadores y sus organizaciones sindicales y políticas, se puede también observar que la presencia de sus construcciones ideológicas previas, el nacionalismo antioligárquico, sigue aún muy extendida en el seno de las masas trabajadoras.

La emancipación de la conciencia del proletariado sólo puede ganarse en lucha total contra la herencia de las ideologías de tipo populista y contra la imposición del dominio corporativista que, apoyado aún en esa ideología, amenaza ahora con impedir el desarrollo de la autonomía de las organizaciones de clase de los trabajadores, y oscurecer aún más su conciencia.

El militarismo fascista que aparece ahora como una de las formas de la dominación burguesa, es ideológicamente un problema diferente. Hoy los trabajadores lo conocen y lo visualizan como un enemigo frontal. Sus secreciones ideológicas sólo podrían aún afectar a algunas de las capas de trabajadores más atrasadas políticamente, y no por mucho tiempo, dadas las condiciones materiales concretas a que esas masas son sometidas. El corporativismo no fascista en cambio, es un fenómeno más complejo. Se funda en reformas parciales, 
en una ideología de conciliación de clase en la herencia populista, tanto desde el punto de vista ideológico, como en el uso del arsenal de técnicas de manipulación política, y se apoya, además, en la simpatía de las corrientes de reformismo obrero-burocrático.

Denomino reformismo obrero-burocrático a una tendencia hoy bastante extendida dentro del movimiento político de los trabajadores, que junto con proclamar explícitamente el socialismo como su meta, funda su acción política concreta en un tipo de razonamiento en que se hibridan, de un lado, la versión burocrática del marxismo y, del otro, formulaciones más o menos radicalizadas - por ser fraseadas en marxismo- de esquemas de análisis social que provienen en gran parte del arsenal ideológico de las capas medias democrático-nacionalistas.

Dependiendo de su grado real de vinculación orgánica con las masas trabajadoras, muy diferente entre los países de América Latina, esta tendencia varía también en su grado de radicalidad y coherencia. En determinados países de reciente industrialización, las organizaciones políticas que contienen esta tendencia han sido generalmente mucho más reformistas y burocráticas que las de otros países, en donde su arraigo en las masas significó siempre un correctivo persistente a una línea igualmente persistente de reformismo obreroburocrático.

Debido a la hibridez de sus bases teóricas y a su vinculación estrecha a la orientación de las necesidades políticas internacionales de los países de Europa del Este, especialmente en los países marcados por la presencia de fuertes corrientes políticas de conducción e ideología pequeñoburguesa, el reformismo obreroburocrático ha tratado y aún trata de ordenar su acción política en función de alianzas con sectores medios o burgueses "progresistas" y en subordinación a ellos, sin intentar siquiera la formulación de alternativas propias de los trabajadores.

Más que en ninguna otra, y sobre todo por más tiempo, es en esta corriente política en donde se encarnan y enraízan, hasta hoy día, los presupuestos teóricos provenientes, al mismo tiempo, de la versión radical de los movimientos populistas de los años treinta y de algunas de las hipótesis marxistas ligadas específicamente a las condiciones históricas del ciclo pasado del capital y de la dominación imperialista, y que se reifican ahora y se convierten en manos de esa corriente, en un puente entre ella y los grupos tecno-burocráticos y burgueses que encabezan el proceso de reajuste de la dominación del capital. 
En ese particular sentido, la lucha contra las bases de la influencia ideológica del populismo en el proletariado, no puede llevarse a cabo plenamente sino también luchando por la erradicación de la influencia del reformismo obrero-burocrático. Porque si bien, considerado en general, éste es un paso adelante en la conciencia proletaria respecto del populismo, es también cierto actualmente que éste se prolonga todavía en la influencia del reformismo obrero-burocrático.

Y, desde luego, las bases teóricas del reformismo en los movimientos populares de América Latina no pueden ser combatidas y erradicadas sino también a través de la lucha contra la influencia del reformismo obrero-burocrático.

El problema de la emancipación de la conciencia política del proletariado, en América Latina, requiere ser pues planteado como una lucha simultánea en tres frentes: contra la herencia ideológica del populismo antioligárquico; contra los intentos de control corporativista de los trabajadores bajo el capitalismo del Estado su ideología de conciliación de clases; y contra la influencia del reformismo obrero-burocrático.

Aquí, sin embargo, es indispensable establecer una distinción necesaria. Cada cual a su manera y en su momento, tramándose hoy día parcialmente, el populismo y el corporativismo provienen totalmente de las secreciones ideológicas de la clase enemiga del proletariado, y sus representantes y portavoces en el seno de los movimientos de los trabajadores son agentes del enemigo. Deben ser, pues, enfrentados sin cuartel.

El reformismo obrero-burocrático, en cambio, sobre todo proviene y se desarrolla desde el interior mismo del proletariado, aunque recogiendo elementos ideológicos de origen pequeñoburgués o burocrático. Representa un estadio atrasado en el desarrollo de la conciencia política de los trabajadores, y en determinadas condiciones las organizaciones que lo expresan, pueden aparecer como aliados de determinadas fracciones del enemigo de clase y al servicio de sus alternativas.

Pero, por su propia naturaleza y origen, por su pertenencia al proletariado, el reformismo obrero-burocrático no puede ser tratado como el enemigo de clase, sino como un fenómeno de desviación contradictoria en el desarrollo político de la clase. La lucha contra él implica pues, en concreto, modalidades y problemas diferentes que en el caso de los anteriores. Depende, en lo fundamental, de las condiciones específicas en que se desarrolla la lucha política del proletariado y de las conductas específicas de 
las organizaciones portadoras del reformismo obrero-burocrático.

\section{LA FORMACIÓN DE UN NUEVO MOVIMIENTO POPULAR REVOLUCIONARIO}

Desde los años veinte de este siglo, en América Latina se desarrollaron movimientos populares que, con grados diversos de radicalidad, estuvieron bajo la conducción ideológica y programática de capas sociales medias.

Hemos visto que las bases estructurales de este tipo de movimientos políticos, están agotándose. Eso no significa, sin embargo, que se hayan cancelado totalmente, ni que la influencia ideológica y la presencia orgánica de tales movimientos hayan sido liquidadas. Aunque en países como Bolivia y Chile, en los últimos años el proletariado pasó claramente a encabezar la movilización popular, en los restantes países sólo muy dificultosamente van abriéndose las posibilidades de un desplazamiento efectivo de la hegemonía política dentro del movimiento popular.

Es claro también, no obstante, que dentro de nuestro esquema de análisis, solamente a través del desarrollo de movimientos popu- lares ideológica y programáticamente conducidos por el proletariado, puede viabilizarse realmente la perspectiva de la revolución latinoamericana, porque las bases para ese desarrollo están ya madurando en el proceso de cambios que estamos registrando.

Se trata, pues, de la formación de un nuevo movimiento popular que para desarrollarse en una dirección real y consecuentemente revolucionaria requiere estar centrada en la hegemonía política del proletariado. Pero, a su turno, para que eso pueda ocurrir, es también indispensable que el proletariado se constituya como una clase revolucionaria, de manera concreta.

Acabamos de ver cómo, para que el proletariado se constituya efectivamente como una clase revolucionaria, la emancipación de la conciencia política de esta clase es una de las condiciones necesarias, y que para ello es indispensable la lucha por la erradicación de los restos de la influencia ideológica de las capas sociales medias, del reformismo obrero-burocrático y contra los intentos o las cristalizaciones de un sistema de dominación política burguesa con rasgos corporativistas.

Esa lucha no puede -para constituir la base del desarrollo revolucionario de la clase- realizarse solamente como desmontaje 
crítico y destrucción teórica de los fundamentos ideológicos, intereses y perspectivas de acción política concreta de aquellas tendencias, ni solamente tratando de llevar a la conciencia de la clase los nuevos factores en que se fundan ahora sus potencialidades políticas propias. Todo ello es indispensable, pero no es suficiente.

Hasta que no se haya desarrollado la capacidad de las clases para ordenar programáticamente sus alternativas de acción, tanto para la lucha por el poder como para sus realizaciones posteriores, la presencia de la influencia política de sus enemigos o de las tendencias reformistas surgidas de su propio seno, condicionará y limitará el proceso de autonomización política de los trabajadores.

En este sentido, debemos decir que actualmente, en la mayor parte de nuestros países, no hemos todavía superado realmente la etapa de la crítica de las alternativas burguesas, pequeñoburguesas u obreras reformistas. Más todavía, que determinadas corrientes revolucionarias que luchan en el seno de movimientos populares bajo conducción burguesa respaldada por capas de burocracia sindical reformista, traducen hoy día como "realismo político" su "apoyo crítico" a esa conducción, sobre la base de esa deficiencia.
Dentro de la brevedad del tiempo, aquí quiero apuntar de paso solamente dos cuestiones, sobre este problema. Primero, algo que quizás por obvio se nos pasa con frecuencia de largo. Yo he visto muchos programas en América Latina, todos hemos visto muchos programas, más o menos interesantes. Pero programa es un concepto científico-político. Y para los marxistas, traduce la base científica del socialismo. Es, por lo tanto, un problema de investigación de la realidad. Implica sacar a luz los problemas, explorar las alternativas de su solución y ordenarlas en un programa de acción. Es, pues, la debilidad de nuestra capacidad de investigación revolucionaria de nuestra realidad, lo que está detrás de la dificultad del proletariado de ordenar programáticamente sus propias alternativas políticas.

En segundo lugar, cuando hablamos de la conducción política del proletariado en un nuevo movimiento popular, que por esa razón central es un movimiento popular revolucionario, aludimos por supuesto a una alianza política de clases dominadas que se orienta por el programa del proletariado. Quiere decir esto, que se trata de un programa que no se refiere solamente a los problemas propios del proletariado, sino también a los de las clases o capas sociales aliadas a él, pero con la particularidad 
de que las alternativas de solución de los problemas de éstas clases o capas sociales, son planteadas en función de los intereses de clase del proletariado, en el largo plazo.

Creo que aquí reside la esencial diferencia entre los movimientos populares conducidos por capas sociales medias y los que son dirigidos por el proletariado. Mientras que en el primer caso se trata de un programa policlasista, en que se articulan soluciones para los intereses del corto plazo de las clases dominadas, en el segundo caso se trata de que los problemas de las clases dominadas puedan enfrentarse a través de alternativas que se vinculen a las necesidades de desarrollo y profundización del proceso revolucionario en una dirección socialista, aunque las formulaciones y procedimientos concretos puedan depender de la correlación de fuerzas políticas de cada momento en cada país determinado.

Además, sobre esta cuestión, me parece todavía conveniente insistir en que -tal como lo he señalado reiteradamente en las reuniones pasadas- el propio concepto de proletariado requiere ser rigurosamente alejado de toda connotación metafísica. Las profundas desigualdades y combinaciones del desarrollo capitalista en América Latina, por la desigualdad de la expansión del capital en cada una de los sectores productivos, y por la superposición de diversas modalidades de acumulación en cada una de ellos, han originado una no menos profunda heterogeneidad en la composición estructural del proletariado, y por eso entre los intereses específicos de sus varias fracciones.

La integración política del proletariado, desde el punto de vista de sus alternativas programáticas, implica por eso mismo la necesidad de investigar y establecer de manera concreta, en cada momento concreto, como pueden ser articulados esos varios intereses específicos con los intereses generales de la clase.

Por lo general, tanto en el terreno sindical, como en el terreno político, las organizaciones del proletariado radican principalmente en las capas y fracciones más concentradas, de mayores ingresos, de mayor nivel de educación tanto escolar como informal, y tienden por eso mismo a orientarse sobre todo en función de los intereses de estos grupos de la clase y no siempre en sus potencialidades de desarrollo ideológico-político. Algunas de las recientes experiencias revolucionarias, como la chilena, han mostrado la dificultad de encontrar formas de articular, tanto orgánica como programáticamente, a esas capas del proletariado con las que corresponden a los otros niveles y modali- 
dades del capital y del proceso de proletarización de los trabajadores.

Desde este punto de vista, es en el seno mismo de ese proletariado concreto, con todas sus diferencias internas de interés específico, que se plantea también el problema de la alianza política, a veces y para determinados países, en un nivel acaso tan decisivo como respecto de las alianzas entre el conjunto del proletariado y las otras clases y capas sociales dominadas. Y ese problema tiene que ser, también, expresado en el propio programa del proletariado.

Finalmente, todos sabemos que la constitución del proletariado como una clase efectivamente revolucionaria, no puede desarrollarse ni consolidarse sino a través del desarrollo de su capacidad de organización y movilización política independiente. Y que hay una dialéctica permanente entre ello y el proceso de emancipación de la conciencia política y del desarrollo de la capacidad política de clase. Es decir, que así como la organización política de la clase se desarrolla en relación a las líneas estratégicas de sus alternativas políticas y a sus programas concretos de acción, éstos dependen igualmente del fortalecimiento de la organización de la clase.

Para no prolongar en exceso esta exposición, quisiera terminarla haciendo sólo unas pocas y breves consideraciones sobre este problema de la organización política.

En primer término, como lo dejé antes señalado, me parece que actualmente en América Latina puede observarse el hecho de que no hemos logrado aún una articulación sistemática, entre nuestros esfuerzos por la organización política de la clase y los vinculados al desarrollo de la teoría y los programas revolucionarios de ella. Y, a mi juicio, a ello se debe que la organización política del proletariado parece ser pensada mucho más en términos de modelos que de programas de organización.

Probablemente coincidiríamos, en abstracto, en que las formas de desarrollo de la organización política de los trabajadores surgen, en cada caso, desde el interior de las determinaciones objetivas concretas de una realidad específica, de la historia de las luchas de clase propias de cada contexto, enriquecidas por la experiencia y las enseñanzas del movimiento revolucionario en el resto del mundo.

Eso, desde luego, implica que los trabajadores de una sociedad concreta, históricamente determinada, no se organizan para cumplir las tareas de una revolución en general, sino para enfrentar, de las maneras que la investigación y la experiencia constante revelan como las más eficaces, los problemas y las tareas revo- 
lucionarias específicas de una situación histórica especifica.

Sin embargo, se puede tener la impresión de que en la etapa actual de nuestras luchas, una parte aún mayoritaria de las corrientes revolucionarias están mucho más dispuestas a ensayar la adaptación de modelos de organización y de acción que ganaron prestigio por su experiencia exitosa en procesos revolucionarios triunfales en otros contextos históricos muy diferentes. El problema es, no obstante, que esos modelos de organización política exitosos fueron en todos los casos el resultado de un trabajo político ordenado teórica y prácticamente, desde el interior mismo de las necesidades y características específicas de la lucha de clases de las respectivas sociedades. ¿O no fue esa la base del surgimiento del tipo de organización bolchevique, a diferencia del de los partidos social-demócratas de Europa Occidental en el mismo periodo? ¿O la combinación de partido y ejército popular revolucionario que conquistó a China para la revolución socialista?

Hoy en América Latina, la izquierda revolucionaria aparece dividida sobre este problema, siguiendo más o menos los siguientes modelos de organización: el modelo bolchevique, que aquí resulta no tanto de la historia real del partido bolchevique en Rusia durante el periodo revolucionario, sino mucho más de la versión burocrática del modelo y de su historia; el modelo maoísta de combinación de partido y ejército popular revolucionario; el modelo "foquista" derivado de la experiencia cubana; el más reciente, que en parte se deriva del anterior, y que se suele denominar como modelo de organización político-militar, en diversas variantes, que traslada la acción guerrillera del escenario rural al urbano. Y hasta hace no mucho tiempo, alguna tendencia política suramericana preconizaba un modelo de organización política basada en los sindicatos, buscando generalizar la experiencia argentina de un momento, en que el movimiento peronista se expresaba principalmente en los sindicatos, sin que en ningún otro país fuera posible observar ninguna situación equivalente.

Esta situación da cuenta de nuestras dificultades y al mismo tiempo de nuestras búsquedas. Particularmente después de la revolución cubana, la experiencia de organización, de movilización, de acción, se ha enriquecido enormemente en nuestros países. Y la entrada creciente de las masas en la escena política, sin duda está desarrollando en todas partes formas y mecanismos de organización, que surgen de la propia experiencia cotidiana de las luchas de estas masas. 
Creo, por eso, que los problemas de organización política no pueden ser tampoco ajenos a la investigación sistemática que permita desde dentro de nuestra propia experiencia pasada y presente, enriquecer la teoría actual sobre la organización revolucionaria, y ordenar nuestras tareas en un programa concreto de organización, apto para recoger y asimilar la experiencia revo- lucionaria, exitosa o frustrada, de otros contextos históricos.

En esta perspectiva, las enseñanzas de Lenin y Mao tienen que ser recuperadas no solamente, y quizás no tanto, en términos de sus fórmulas específicas, elaboradas para su propia circunstancia y lucha, sino ante todo en términos de su metodología que, básicamente, consiste en investigar la realidad concreta y partir de ella. 